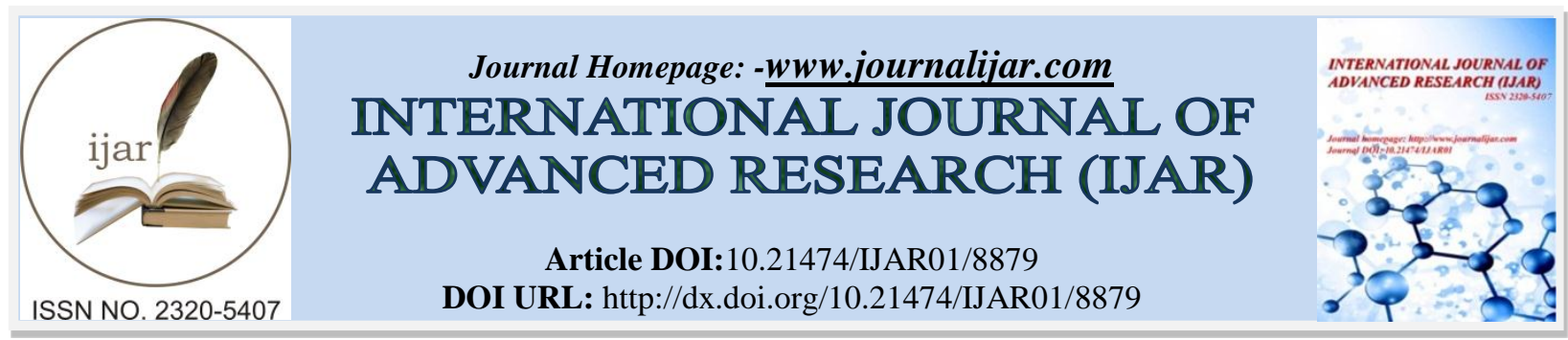

RESEARCH ARTICLE

\title{
ASSOCIATION OF SONOGRAPHIC POLYHYDRAMNIOS WITH PRETERM BIRTH.
}

Ayesha Tariq, Mishal Javaid, Muhammad Zubair, Sarah Maryam, Yousef Gilani and Syed Amir Gilani. University Institute of Radiological Sciences and Medical Imaging Technologies, Faculty of Allied Health Sciences, University of Lahore, Lahore, Pakistan.

\section{Manuscript Info}

\section{Manuscript History}

Received: 11 February 2019

Final Accepted: 13 March 2019

Published: April 2019

Keywords:-

Amniotic fluid index, Preterm birth, Polyhydramnios, Adverse perinatal outcomes.

\begin{abstract}
Polyhydramnios carries a high rate of complications during pregnancies and adverse perinatal outcomes. The aim of this study was to evaluate the risk of preterm birth in patients with polyhydramnios.

Objective: To determine the association of sonographic polyhydramnios with preterm birth.

Methods: A cross-sectional Analytical study was carried out at the Department of Radiology in Sir Ganga Ram Hospital Lahore, Pakistan. Duration of study was from March 2018 to November 2018. Patients in $2^{\text {nd }}$ and $3^{\text {rd }}$ trimester of pregnancy with Polyhydramnios were chosen subsequent to fulfil consideration (inclusion) and rejection (exclusion) criteria. A complete history and investigation were finished. All necessary examination is done. Polyhydramnios confirmed by estimating AFI. Statistical Software for Social Sciences (SPSS version 22.0) is used for the analysis of all data. Standard and Mean Deviation (SD) remained calculated for continuous variables.

Results: Total of 64 patients were diagnosed in this study. The Mean \pm S.D age was $26.92 \pm 3.55$ years. Out of 51 patients of 21-29 age group 42 were diagnosed with polyhydramnios and 9 were without polyhydramnios and 23 patients had full-term deliveries and 28 patients had preterm deliveries. In 30-38 age group total 13 patients out of which 10 patients with polyhydramnios and 3 patients without polyhydramnios and 4 patients had full-term deliveries and 9 patients had preterm deliveries. Minimum AFI is 8.0 and Maximum AFI 55.0 with Mean \pm S.D of $26.70 \pm 9$ 9.40. Minimum GA was 141 and Maximum GA 244 days with Mean \pm S.D of $244.95 \pm$ 27.07. 27. Patients were full-term delivery out of 18 patients have polyhydramnios and 9 patients have no polyhydramnios. 37 patients were preterm delivery out of which 34 Patients have polyhydramnios and 3 patients have no polyhydramnios.

Conclusion: This study concluded that excess of amniotic fluid lead towards preterm birth. This is also found patients of 21-29 ages were more prone to polyhydramnios.
\end{abstract}

Copy Right, IJAR, 2019, All rights reserved.

Corresponding Author:-Ayesha Tariq.

Address:-University Institute of Radiological Sciences and Medical Imaging Technologies, Faculty of Allied Health Sciences, University of Lahore, Lahore, Pakistan. 


\section{Introduction:-}

Polyhydramnios is a medical condition describing an excess of amniotic fluid in the amniotic sac ${ }^{1}$. Polyhydramnios is generally detected either by physical examination if the uterus appears larger or measures larger than expected by the pregnancy dating, by sonography at the time of the fetal anatomic survey, or when the development of other conditions warrants assessment of the amniotic fluid or fetal growth during a pregnancy ${ }^{2}$. Amniotic fluid provides an optimal environment for normal fetal growth and development. The AFV is the result of a series of complex and dynamic pathways influencing the movement of fluid into and out of the amniotic space. This balance is regulated by mechanisms that are not yet completely understood ${ }^{3}$. The main sources determining the AFV include fetal urine production, fetal swallowing, secretion of fetal lung fluid, movement of water and solutes between fetal blood and the placenta (intramembranous pathway), movement of water and solutes across the surface of the amnion and chorion (trans membranous pathway), secretions by the fetal oral and nasal cavities, and movement of fluid across fetal skin during early gestation ${ }^{4}$. A disturbance in any of these processes can result in an abnormally low or high $\mathrm{AFV}$, referred to as oligohydramnios or polyhydramnios, respectively. The main routes of amniotic fluid removal are fetal swallowing and absorption via the intramembranous pathway ${ }^{3}$. Polyhydramnios can result from an imbalance in any of these pathways. Decreased elimination of amniotic fluid, either from anomalies (e.g., choanal atresia, esophageal atresia, tracheoesophageal fistula, and duodenal or intestinal atresia) or as a result of reduced swallowing ability or function, which can be due to neurologic impairment (e.g., anencephaly) or neuromuscular disorders (eg, myotonic dystrophy), drug-induced, or potentially a result of fetal hypoxia as evidenced in the ovine model, can all result in hydramnios ${ }^{5}$. Polyhydramnios has three terms the terms mild, moderate, and severe have been used to describe degrees of polyhydramnios. Mild hydramnios has been defined as an AFI of 25 to $30 \mathrm{~cm}$ or an SDP of $8 \mathrm{~cm}$ or greater, moderate hydramnios as an AFI of 30.1 to $35 \mathrm{~cm}$ or an SDP of $12 \mathrm{~cm}$ or greater, and severe hydramnios as an AFI of $35.1 \mathrm{~cm}$ or greater or SDP of $16 \mathrm{~cm}$ or greater ${ }^{6}$. Increasing severity of polyhydramnios appears to correlate with an increased risk of perinatal mortality and congenital abnormalities ${ }^{7}$. Polyhydramnios is associated with fetal and maternal complications such as respiratory distress, thromboembolism, preterm labour, atonic uterus, anaemia, caesarean section, premature fetus, umbilical cord prolapse caused by the rupture of the membranes and fetal distress ${ }^{8}$. A fetus close to term will produce between $500-1200 \mathrm{ml}$ urine and swallow between 210-760 ml of amniotic fluid per day. Even small changes in this equilibrium can result in significant changes in amniotic fluid volumes ${ }^{9}$. A disturbed equilibrium can be the result of compromised swallowing function or increased urination and can lead to polyhydramnios ${ }^{9}$. Increased urine production, as occurs with increased cardiac output associated with fetal anaemia, can also result in increased production of amniotic fluid ${ }^{10}$.

The risk of the preterm birth, umbilical cord prolapse is increased when polyhydramnios is present due to overexpansion of the uterus ${ }^{11}$. The rate of preterm delivery at $<34$ weeks increases as the maximal AFI increases, and reaches $19.4 \%$ with an AFI $\geq 35 \mathrm{~cm}^{12}$. Preterm labour and subsequent preterm delivery are often thought to be directly related to polyhydramnios, as a result of the increasing volume of amniotic fluid. This correlation is reasonable to make considering that the increasing distention of the uterus can result in uterine contractions. Thus, one would expect there to be a higher rate of preterm labour and preterm delivery in those women with increasingly higher AFVs correlating with increasing severity of polyhydramnios ${ }^{2}$. Preterm birth, defined as delivery prior to 37 completed weeks, is a public health priority Because preterm birth can result in significant morbidities and mortalities ${ }^{13,14}$. Premature birth is a birth that takes place more than three weeks before the baby's estimated due date. In other words, premature birth is one that occurs before the start of the 37th week of pregnancy. Very preterm, born at less than 32 weeks of pregnancy. Extremely preterm, born at or before 25 weeks of pregnancy ${ }^{15}$.

Ultrasound is still a useful diagnostic and follow-up modality in polyhydramnios patients ${ }^{16}$. Clinically, polyhydramnios is identified using either the clinician's subjective impression of an increased amount of amniotic fluid during a sonographic assessment or using a sonographic measurement to estimate the amniotic fluid volume (AFV). Two commonly used sonographic measurements that suggest a high volume of amniotic fluid include an amniotic fluid index (AFI) of $25 \mathrm{~cm}$ or greater or a single deepest pocket (SDP) of $8 \mathrm{~cm}$ or greater ${ }^{17}$. In mild cases, simple control and follow-ups, continuous ultrasound and conservative treatment methods are recommended ${ }^{18}$. It is also the method of choice in multiple gestations. In cases with multiple gestations, a range of $3-8 \mathrm{~cm}$ is defined as normal. With this method, polyhydramnios is classified as mild, moderate or severe ${ }^{19}$ For the 4-quadrant method (AFI - Amniotic Fluid Index) the deepest amniotic pocket in each of the four quadrants is measured vertically and the values added together ${ }^{20}$. Inclusion Criteria: Singleton pregnancies in between $16-42$ weeks of gestation. Polyhydramnios with an amniotic fluid index of at least $25 \mathrm{~cm}$. Exclusion Criteria: Patient with uterine anomalies, multiple pregnancies and fetal chromosomal anomalies. 


\section{Methods:-}

A cross-sectional Analytical study was carried out at the Department of Radiology in Sir Ganga Ram Hospital Lahore, Pakistan. Duration of study was from March 2018 to November 2018. Patients in $2^{\text {nd }}$ and $3^{\text {rd }}$ trimester of pregnancy with Polyhydramnios were chosen subsequent to fulfil consideration (inclusion) and rejection (exclusion) criteria. A complete history and investigation were finished. All necessary examination is done. Polyhydramnios confirmed by estimating AFI. Statistical Software for Social Sciences (SPSS version 22.0) is used for the analysis of all data. Standard and Mean Deviation (SD) remained calculated for continuous variables.

\section{Results:-}

Out of 64 patients, the Mean \pm S.D age was $26.92 \pm 3.55$. The Minimum age of patient were 21 and Maximum age 38 in table 1 , figure 1.

Table 1:-Descriptive statistics of Age

\begin{tabular}{|l|r|r|r|r|r|}
\hline & $\mathrm{N}$ & \multicolumn{1}{|c|}{ Minimum } & Maximum & \multicolumn{1}{c|}{ Mean } & Std. Deviation \\
\hline Age & 64 & 21 & 38 & 26.9219 & 3.55592 \\
\hline $\mathrm{N}$ & 64 & & & & \\
\hline
\end{tabular}

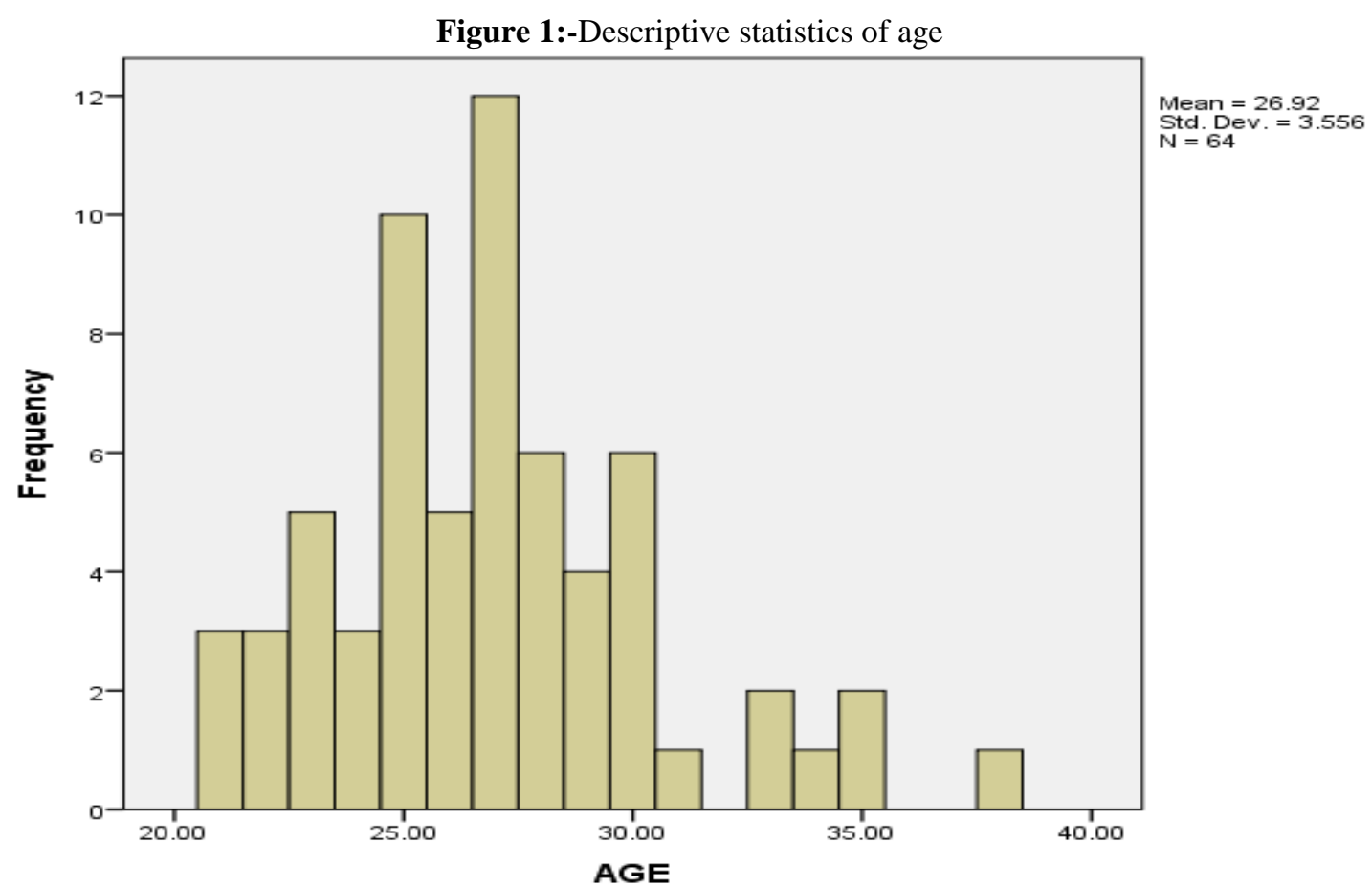

According to table 1.1, Group A age 21-29 and total patients 51 out of which 42 patients with polyhydramnios and 9 patients without polyhydramnios. Group B age 30-38 and a total 13 patients out of which 10 patients with polyhydramnios and 3 patients without polyhydramnios

\begin{tabular}{|l|r|r|r|r|}
\hline \multicolumn{2}{|c|}{ Count } & \multicolumn{2}{|c|}{ Other reason } & \multirow{2}{*}{ Total } \\
\cline { 3 - 4 } \multicolumn{2}{|c|}{} & with polyhydramnios & without polyhydramnios & \\
\hline \multirow{2}{*}{ Age groups } & $21----29$ & 42 & 9 & 51 \\
\cline { 2 - 5 } & $30---38$ & 10 & 3 & 13 \\
\hline Total & 52 & 12 & 64 \\
\hline
\end{tabular}

Table 1.1:-Group wise age distribution with and without polyhydramnios 


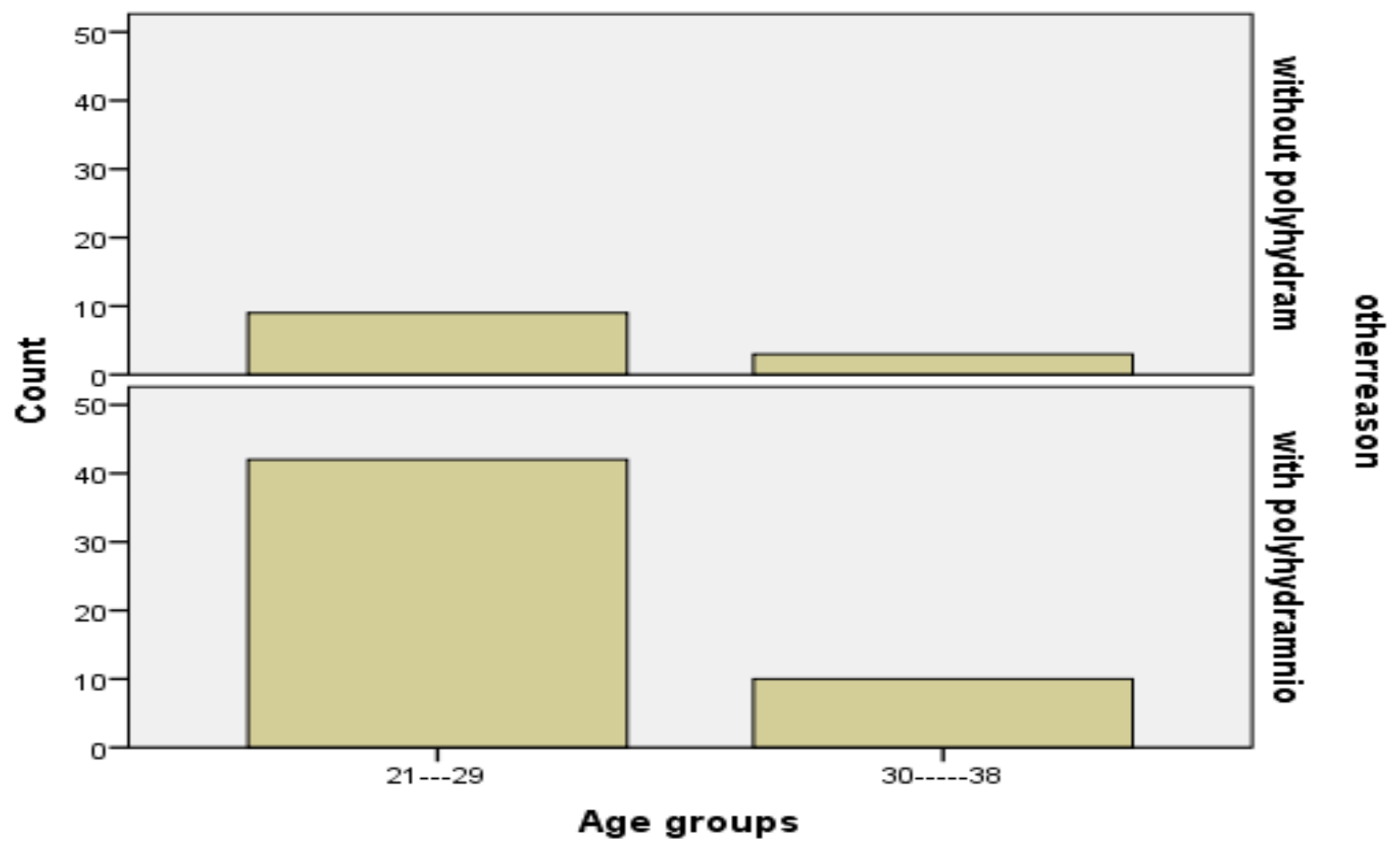

Table 1.1:-Group wise age distribution with and without polyhydramnios

Table number 1.2 show that Group A, age $21-29,23$ patients had full-term deliveries and 28 patients had preterm deliveries out of 51. Group B age 30-38, 4 patients had full-term delivery and 9 patients had preterm delivery out of 13 .

\begin{tabular}{|l|l|r|r|r|}
\hline \multicolumn{2}{|c|}{} & \multicolumn{2}{|c|}{ Delivery } & \multicolumn{2}{c|}{ Total } \\
\cline { 3 - 5 } \multicolumn{2}{|c|}{} & Full term & preterm & 51 \\
\hline Age groups & $21---29$ & 23 & 28 & 13 \\
\cline { 2 - 5 } & $30----38$ & 4 & 9 & 64 \\
\hline Total & 27 & 37 & \\
\hline
\end{tabular}

Table 1.2:-Age wise distribution according to full term and preterm deliveries

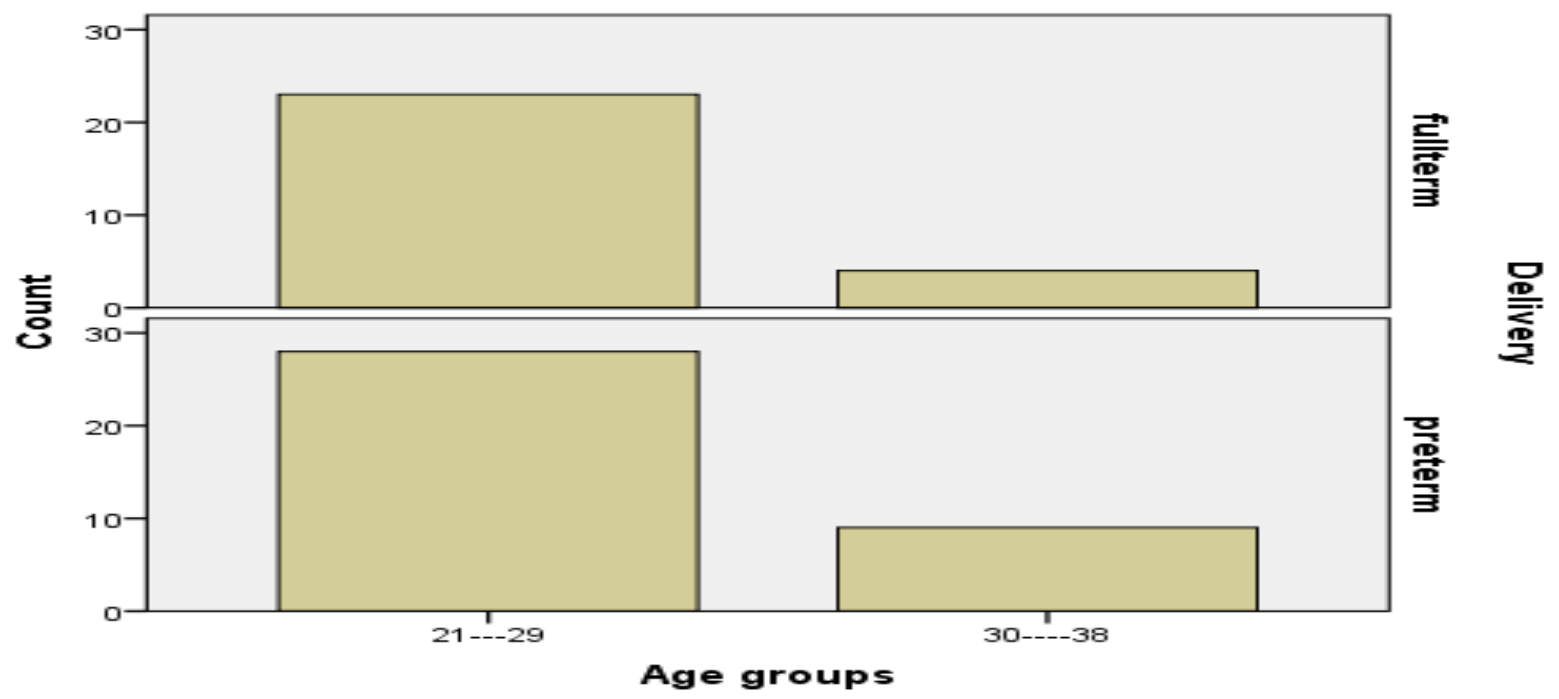

Fig 1.2:-Age wise distribution according to full term and preterm deliveries. 
According to table 1.3, in the age group 21-29, out of 42 of polyhydramnios patients, 16 had full term and 26 had preterm labour. And without polyhydramnios, 7 had full term and 2 had preterm out of 9. In age group 30-38, out of 10 of polyhydramnios patients, 2 had full term and 8 had preterm. And without polyhydramnios, 2 had full term and 1 had preterm out of 3 .

\begin{tabular}{|c|c|c|c|c|c|}
\hline \multicolumn{3}{|c|}{ Age groups } & \multicolumn{2}{|c|}{ Delivery } & \multirow[t]{2}{*}{ Total } \\
\hline & & & Full term & preterm & \\
\hline \multirow[t]{3}{*}{$21---29$} & \multirow[t]{2}{*}{ Other reason } & with polyhydramnios & 16 & 26 & 42 \\
\hline & & without polyhydramnios & 7 & 2 & 9 \\
\hline & \multicolumn{2}{|l|}{ Total } & 23 & 28 & 51 \\
\hline \multirow[t]{3}{*}{$30----38$} & \multirow[t]{2}{*}{ Other reason } & with polyhydramnios & 2 & 8 & 10 \\
\hline & & without polyhydramnios & 2 & 1 & 3 \\
\hline & \multicolumn{2}{|l|}{ Total } & 4 & $\overline{9}$ & 13 \\
\hline \multirow[t]{3}{*}{ Total } & \multirow[t]{2}{*}{ Other reason } & with polyhydramnios & 18 & 34 & 52 \\
\hline & & without polyhydramnios & 9 & 3 & 12 \\
\hline & \multicolumn{2}{|l|}{ Total } & 27 & 37 & 64 \\
\hline
\end{tabular}

Table 1.3: the -Other reason for delivery according to age groups

According to table 2 and figure 2, The Minimum AFI is 8.0 and Maximum AFI 55.0 with Mean \pm S.D of $26.70 \pm$ 9.40 .

\begin{tabular}{|c|r|r|r|r|r|}
\hline & N & Minimum & Maximum & \multicolumn{1}{c|}{ Mean } & Std. Deviation \\
\hline Amniotic Fluid Index (AFI) & 64 & 8.00 & 55.00 & 26.7031 & 9.40564 \\
\hline N & 64 & & & & \\
\hline
\end{tabular}

Table 2:-Descriptive statistics of AFI

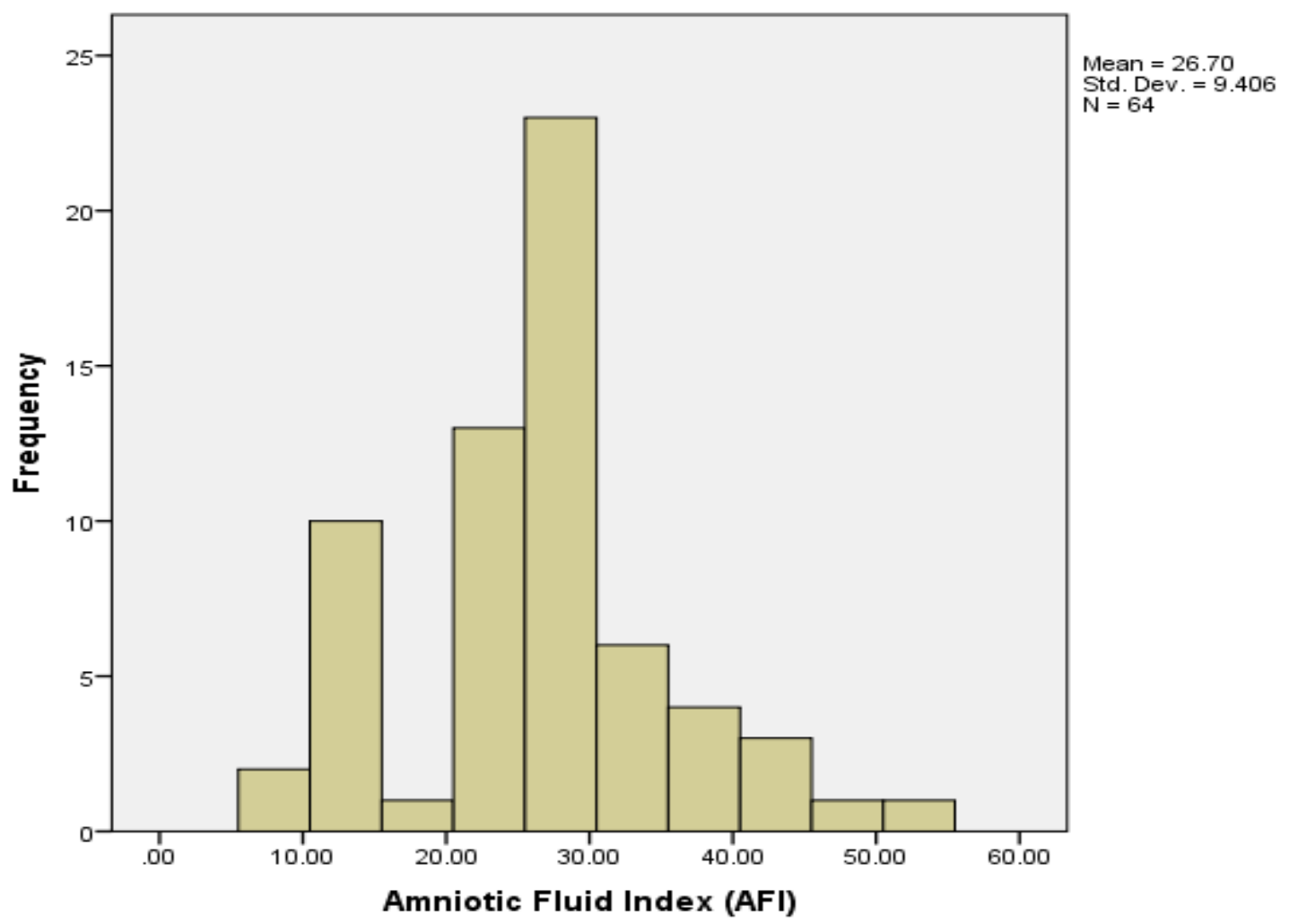

Figure 2:-Descriptive statistics AFI 
According to table number 3 and figure 3, Minimum GA was 141 and Maximum GA 244 days with Mean \pm S.D of gestational age was $244.95 \pm 27.07$ of 64 females.

\begin{tabular}{|l|r|r|r|r|r|}
\hline \multicolumn{7}{|c|}{ Descriptive Statistics } \\
\hline & $\mathrm{N}$ & Minimum & Maximum & Mean & Std. Deviation \\
\hline $\begin{array}{l}\text { Gestational age (GA) in } \\
\text { days }\end{array}$ & 64 & 141.00 & 280.00 & 244.9531 & 27.07804 \\
\hline & & & & & \\
\hline
\end{tabular}

Table 3:-Descriptive statistics gestational age

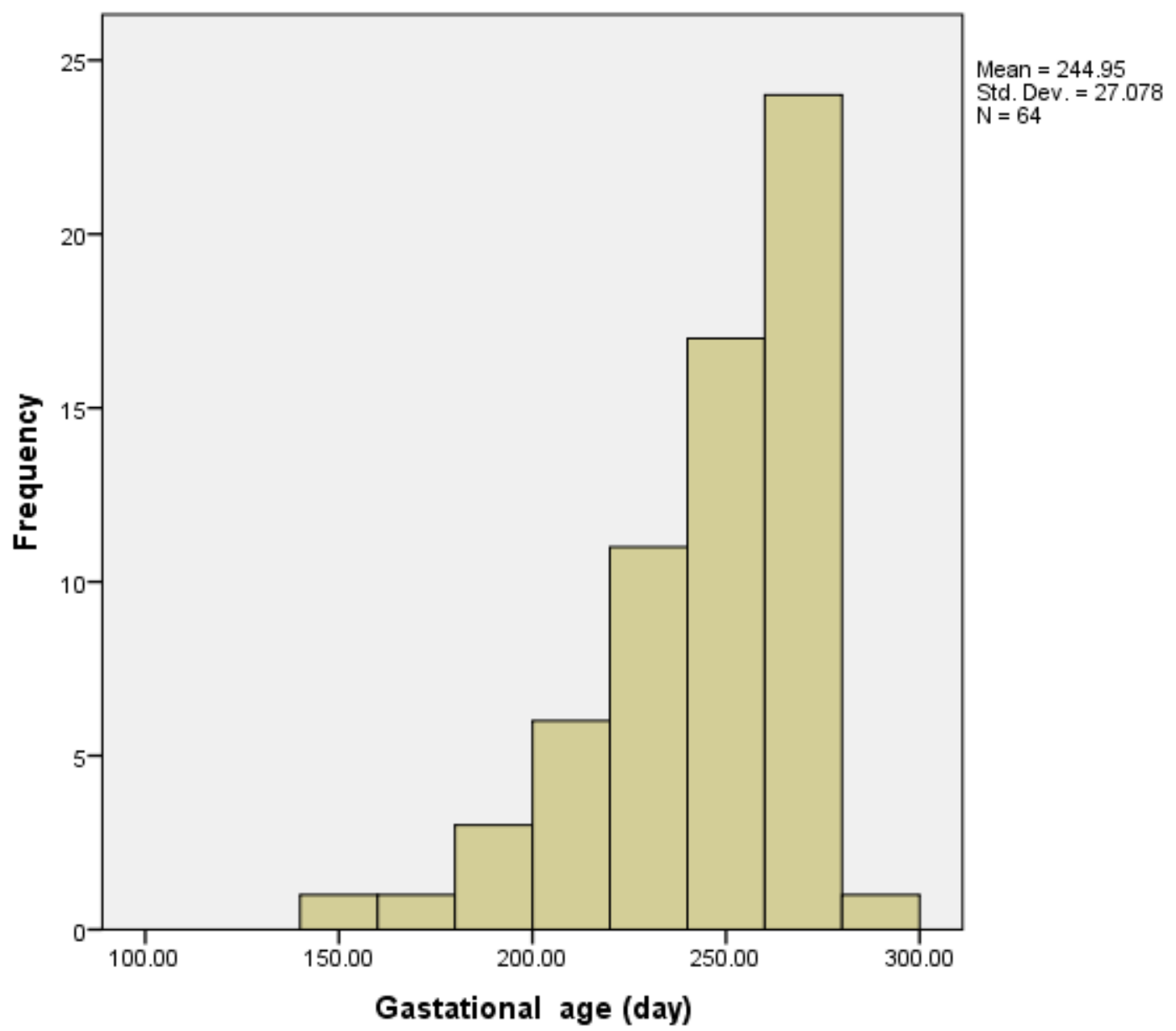

Figure 3:-Descriptive statistics gestational age

Total 64 patients, 27 patients were full-term delivery out of 18 patients have polyhydramnios and 9 patients have no polyhydramnios. 37 patients were preterm delivery out of which 34Patients have polyhydramnios and 3 patients have no polyhydramnios in table number 4 and figure 4.

Delivery * other reason Cross tabulation

\begin{tabular}{|l|l|r|r|r|}
\hline \multicolumn{2}{|c|}{} & \multicolumn{2}{|c|}{ Other reason } & \multirow{2}{*}{ Total } \\
\cline { 3 - 4 } \multicolumn{2}{|c|}{} & with polyhydramnios & $\begin{array}{c}\text { without } \\
\text { polyhydramnios }\end{array}$ & \\
\hline \multirow{2}{*}{ Delivery } & Full term & 18 & 9 & 27 \\
\cline { 2 - 5 } & preterm & 34 & 3 & 37 \\
\hline
\end{tabular}




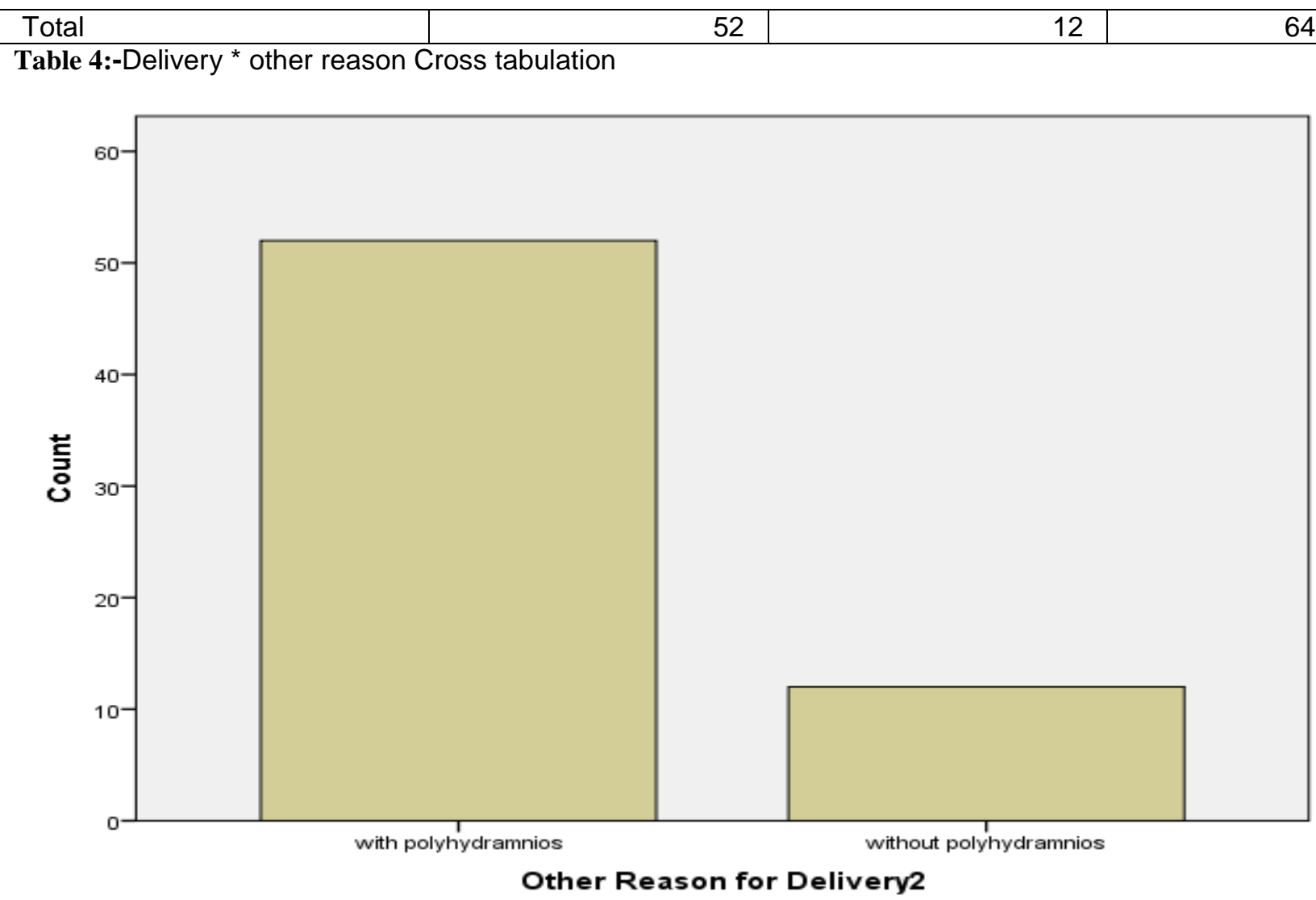

Figure 4.1:-Delivery with polyhydramnios and without polyhydramnios

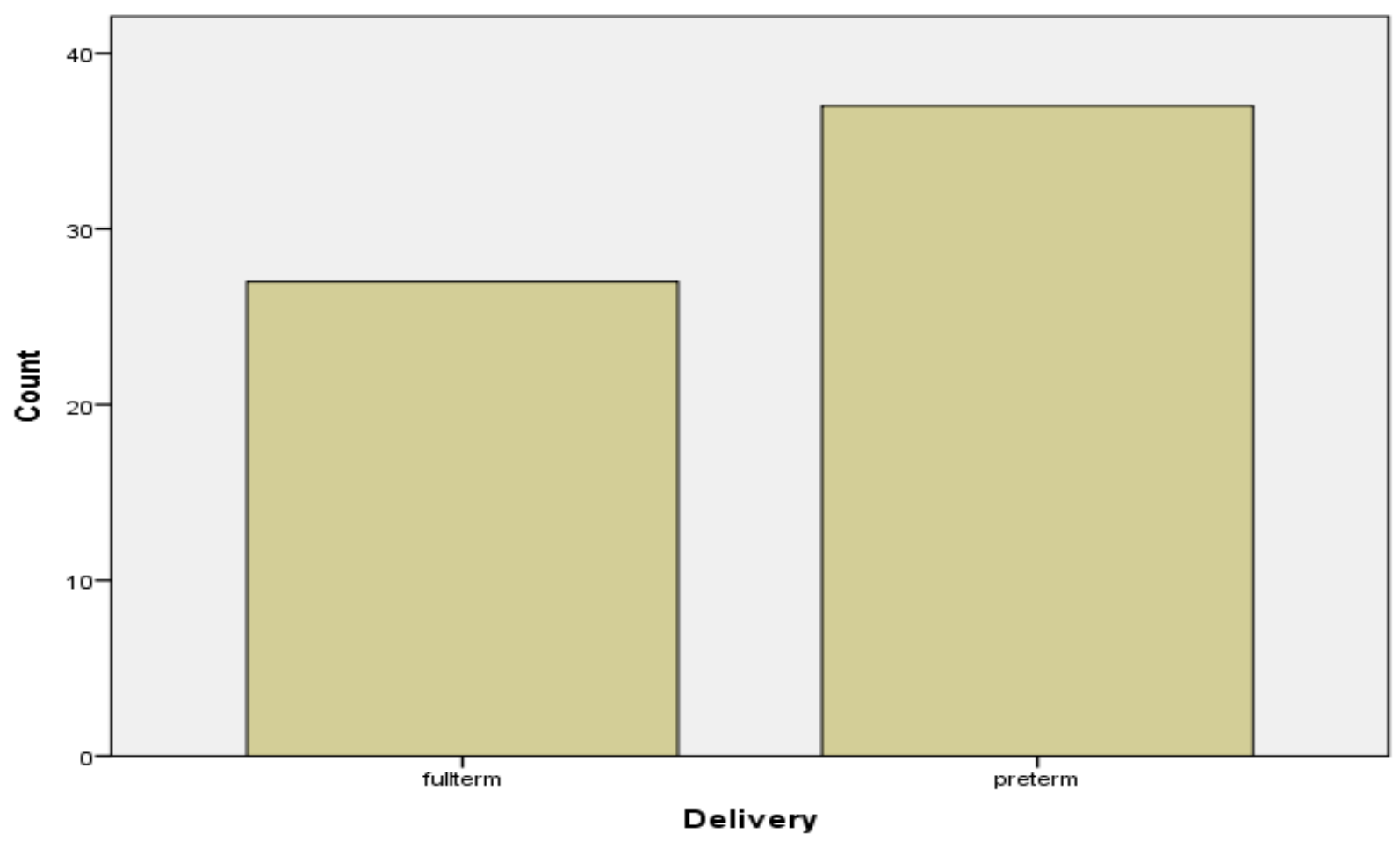

Fig 4.2:-Delivery with the full term and preterm 


\begin{tabular}{|l|c|r|r|r|r|}
\hline & Value & Df & $\begin{array}{c}\text { Asymp. Sig. } \\
\text { (2-sided) }\end{array}$ & $\begin{array}{c}\text { Exact Sig. (2- } \\
\text { sided) }\end{array}$ & $\begin{array}{c}\text { Exact Sig. (1- } \\
\text { sided) }\end{array}$ \\
\hline Pearson Chi-Square & $6.520^{\mathrm{a}}$ & 1 & .011 & & \\
\hline Continuity Correction & 4.969 & 1 & .026 & & \\
\hline Likelihood Ratio & 6.574 & 1 & .010 & & .013 \\
\hline Fisher's Exact Test & & & & & \\
\hline N of Valid Cases & 64 & & & & \\
\hline
\end{tabular}

\section{Discussion:-}

The current research was designed to determine the association of sonographic polyhydramnios with preterm birth. The results of my study were comparable with the result of the research conducted by Ahkam Goksel et al, (2013) studied on Perinatal outcomes of idiopathic Polyhydramnios. This study was conducted at the department of obstetrics from 2008 to 2010. Retrospective analysis of 160 singleton pregnancies that were under routine surveillance at the department of obstetrics from 2008 to 2010 was performed to assess perinatal outcomes. 59 cases were included as idiopathic Polyhydramnios and 101 cases were included as controls. Preterm delivery ( $<37$ weeks) was selected. A result shows that significantly higher preterm labours were noted in the polyhydramnios group compared with the control group. In the end, he concluded that although perinatal outcomes are conflicting in literature, idiopathic polyhydramnios warrants close surveillance, especially near term. The result of my study shows that there was an association of polyhydramnios with preterm birth but preterm birth also occurs due to many other reasons. Ultrasonography is almost always a decent beginning decision and is uncomplicated circumstances, might be all that is required. So my study agrees with the others study that apart from the affectability and specificity of ultrasound, it is non-invasive, readily available, portable and inexpensive.

\section{Conclusion:-}

The significant value of the current study is .021, so it's justified to state that there is an association of polyhy dramnios with preterm birth.

\section{Reference:-}

1. Nelson DB, Ziadie MS, McIntire DD, Rogers BB, Leveno KJ. Placental pathology suggesting that preeclampsia is more than one disease. American journal of obstetrics and gynaecology 2014;210(1):66. e1-. e7.

2. Sandlin AT, Chauhan SP, Magann EF. Clinical relevance of sonographically estimated amniotic fluid volume: polyhydramnios. Journal of Ultrasound in Medicine 2013;32(5):851-63.

3. Magann EF, Sandlin AT, Ounpraseuth ST. Amniotic fluid and the clinical relevance of the sonographically estimated amniotic fluid volume: oligohydramnios. Journal of Ultrasound in Medicine 2011;30(11):1573-85.

4. Modena AB, Fieni S. Amniotic fluid dynamics. Acta bio-medica: Atenei Parmensis 2004;75:11-3.

5. Brace RA, Wlodek ME, Cock ML, Harding R. Swallowing of lung liquid and amniotic fluid by the ovine fetus under normoxic and hypoxic conditions. American journal of obstetrics and gynaecology 2000;171(3):764-70.

6. Lazebnik N, Many A. The Severity of Polyhydramnios, Estimated Fetal Weight and Preterm Delivery Are Independent Risk Factors for the Presence of Congenital Malformation s. Gynecologic and obstetric investigation 2001;48(1):28-32.

7. Bundgaard A, Ristorp Andersen B, Rode L, Lebech M, Tabor A. Prevalence of polyhydramnios at a Danish hospital-a population-based study. Acta obstetrician et Gynecologica Scandinavica 2007;86(12):1427-31.

8. Khan S, Donnelly J. Outcome of pregnancy in women diagnosed with idiopathic polyhydramnios. Australian and New Zealand Journal of Obstetrics and Gynaecology 2017;57(1):57-62.

9. Hamza A, Herr D, Solomayer E, Meyberg-Solomayer G. Polyhydramnios: causes, diagnosis and therapy. Geburtshilfe und Frauenheilkunde 2013;73(12):1241.

10. Lee S, Jun J, Lee E, Lee J, Park CW, Park J, et al. Measurement of fetal urine production to differentiate causes of increased amniotic fluid volume. Ultrasound in Obstetrics and Gynecology 2010;36(2):191-5.

11. Magann EF, Doherty DA, Lutgendorf MA, Magann MI, Chauhan SP, Morrison JC. Peripartum outcomes of high-risk pregnancies complicated by oligo-and polyhydramnios: A prospective longitudinal study. Journal of Obstetrics and Gynaecology Research 2010;36(2):268-77.

12. Pri-Paz S, Khalek N, Fuchs K, Simpson L. Maximal amniotic fluid index as a prognostic factor in pregnancies complicated by polyhydramnios. Ultrasound in Obstetrics \& Gynecology 2012;39(6):648-53. 
13. Raju TN, Higgins RD, Stark AR, Leveno KJ. Optimizing care and outcome for late-preterm (near-term) infants: a summary of the workshop sponsored by the National Institute of Child Health and Human Development. Paediatrics 2006;118(3):1207-14.

14. Sangeetha K. Pregnancy outcome in an amniotic fluid index is less than five in term low-risk pregnancy. 2013.

15. Shyam S, Ramadas A. Treatments with Low Glycaemic Index Diets in Gestational Diabetes. In: Nutrition and Diet in Maternal Diabetes: Springer; 2018. p. 237-51.

16. Hershkovitz R, Sheiner E, Maymon E, Erez O, Mazor M. Cervical length assessment in women with idiopathic polyhydramnios. Ultrasound in obstetrics \& gynaecology 2006;28(6):775-8.

17. Suleiman A, Salim R. Mode of delivery among women admitted with polyhydramnios. Journal of Obstetrics and Gynaecology 2017;37(4):454-8.

18. McKinlay CJ, Cutfield WS, Battin MR, Dalziel SR, Crowther CA, Harding JE. Mid-childhood bone mass after exposure to repeat doses of antenatal glucocorticoids: a randomized trial. Pediatrics 2017;139(5):e20164250.

19. Chen M, Chen C-P. Invasive fetal therapy: global status and local development. Taiwanese Journal of Obstetrics and Gynecology 2004;43(4):185-92.

20. Magann EF, Chauhan SP, Doherty DA, Lutgendorf MA, Magann MI, Morrison JC. A review of idiopathic hydramnios and pregnancy outcomes. Obstetrical \& gynecological survey 2007;62(12):795-802. 